\title{
DOENÇA PULMONAR INTERSTICIAL SECUNDÁRIA À DERMATOMIOSITE AMIOPÁTICA COM ANTICORPO ANTI-MDA-5 POSITIVO
}

\begin{abstract}
Autores : MÔNICA DUARTE COSTA ${ }^{1,2}$; CARLOS ALBERTO DE CASTRO PEREIRA ${ }^{3}$, DANIELLE RESEGUE ANGELIERI ${ }^{1,2}$, ELISA TEREZINHA HACBARTH FREIRE ${ }^{1,2}$, LEANDRO PARMIGIANI ${ }^{1,2}$, LUIS CARLOS LOSSO ${ }^{1}$, MARILIA CARVALHO VIEIRA LEARTH CUNHA ${ }^{1}$, MARINA DORNFELD CUNHA CASTRO ${ }^{1}$, TACIANA PAULA DE SOUZA STACCHINI 1,2 , THEMIS MIZERKOWSKI TORRES 2
\end{abstract}

1 Médico do Hospital Professor Edmundo de Vasconcelos 2 Médico da Clínica RECRIAR

3Unifesp

\section{Relevância do Caso}

As doenças intersticiais pulmonares (DPIs) são um grupo heterogêneo de pneumopatias de diferentes causas. 0 diagnóstico etiológico é extremamente importante pois define o tratamento e o prognóstico.

O acometimento pulmonar pode representar a manifestação inicial e/ou dominante nas doenças do tecido conjuntivo (DTCs). Manifestações extratorácicas devem ser sistematicamente consideradas e, quando presentes, auto-anticorpos (ac) podem contribuir para o diagnóstico da DPI secundária à DTC.

O presente relata um caso raro e inédito no Brasil de DPI relacionado a dermatomiosite (DM) ac anti-MDA-5 positivo.

\section{Relato de Caso}

Sexo feminino, 34 anos, internada por dispneia progressiva ate moderados esforços há 2 meses, tosse seca e dorsalgia. Negava febre, sintomas de rinossinusopatia ou gastroesofágicos. Negava artralgia, fraqueza proximal ou fenômeno de Raynaud. Ex-tabagista 3 maços/ano, cessado há 2 anos. Negava exposições ocupacionais e ambientais.

Ao exame físico bom estado geral, estertores finos basais, saturação de oxigênio de $98 \%$ (ar ambiente); discretas máculas eritemato-violáceas nas pálpebras, tronco anterior e posterior e superfícies extensoras dos cotovelos, discretas pápulas violáceas nas articulações interfalangeanas distais das mãos e leve descamação da pele da região lateral dos quirodáctilos.

TCAR de tórax com opacidades esparsas, centrais e periféricas, predomínio basal e atelectasias segmentares. Hemograma normal, FAN 1/160 pontilhado fino, aldolase 8,7 U/L (normal até 7), CPK 74U/L (normal até 190 ) e demais acs incluindo anti-Jo1 negativos.

Avaliada pela equipe da cirurgia torácica que indicou biópsia por videotoracoscopia. Anatomopatológico: lesão subaguda com focos de pneumonia em organização, espessamento septal difuso e homogêneo com padrão de pneumonia não específica, acúmulos linfoides e pleurite crônica discreta e focal.

Evoluiu com piora clínica (hipoxemia e dispneia aos mínimos esforços) e tomográfica, sendo tratatada com pulsoterapia com metilprednisolona e, pela possibilidade de processo infeccioso sobreposto, imunoglobulina e antibioticoterapia de amplo espectro.

Alta com oxigenoterapia contínua, prednisona e azatioprina.

Realizado painel de auto-anticorpos relacionados a miopatias (laboratório no exterior) que demonstrou ac anti-melanoma differentiation-associated gene 5 (anti-MDA-5) positivo, com diagnóstico final de DPI secundária à DM amiopática.
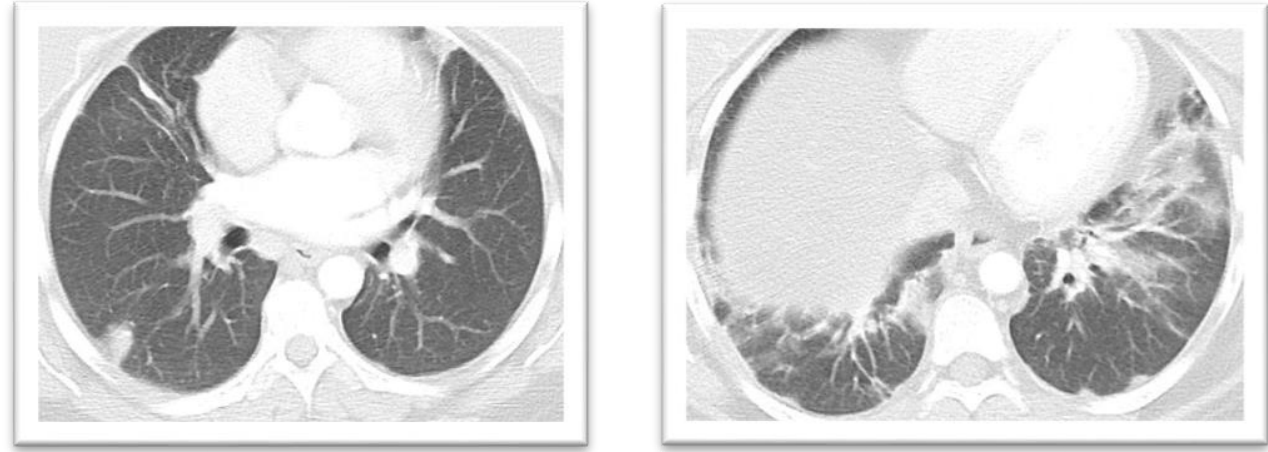

Tomografia computadorizada: opacidades periféricas e centrais e atelectasias basais.

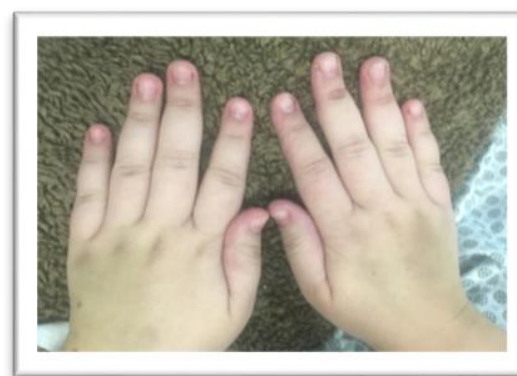

Exame físico: lesões cutâneas em mãos.

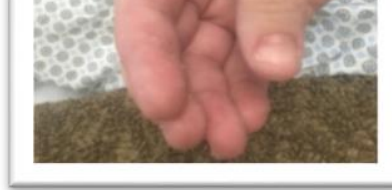

\section{Discussão}

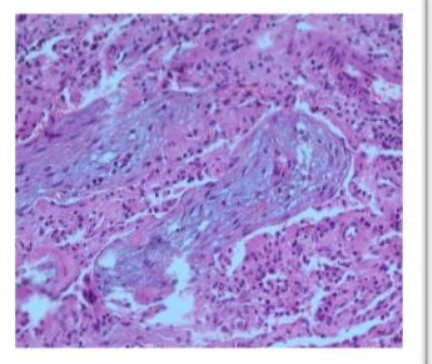

Anatomopatológico de biópsia pulmonar: focos de pneumonia em organização.
As miopatias inflamatórias idiopáticas (MIIIs) caracterizam-se por lesão musculoesquelética imunomediada com diversos tipos e graus de miosites e manifestações extramusculares, incluindo cutâneas e pulmonares.

A dermatomiosite é o subtipo mais comum. Inclui sinais cutâneos rash periorbital violáceo e edematoso (sinal de heliótropo), lesões eritematosas em articulação dos dedos (sinal de Gottron), erupção cutânea em área fotoexposta e mãos de mecânico (hiperqueratose na face lateral dos dedos). As manifestações musculares são variáveis e podem não estar presentes (forma amiopática). As manifestações pulmonares podem preceder as musculares em mais de $1 / 3$ dos casos, sendo a DPI a mais prevalente.

A DPI está presente em 3 a cada 4 casos de MII, sendo a manifestação não-musculoesquelética mais comum, a $2^{\text {a }}$ causa de morbidade e a principal causa de mortalidade.

Algumas condições estão associadas a maior risco para envolvimento pulmonar. A síndrome do anticorpo antissintetase caracterizada pela combinação de mãos de mecânico, fenômeno de Raynaud, miosite (geralmente leve ou ausente) e positividade para um dos anticorpos anti-tRNA, está associada à $70 \%$ de risco para DPI, em especial quando o ac anti-Jo1 está presente. Na DM amiopática relatase maior frequência de DPI rapidamente progressiva e pior função pulmonar, principalmente na presença de ac anti-MDA-5 positivo. Esse anticorpo específico ocorre em 7 a $13 \%$ dos adultos com DM, principalmente sem miopatia. Ainda é fator preditivo positivo para menor taxa de sobrevida e desenvolvimento de úlceras distais dolorosas.

\section{Conclusão}

O relato destaca o diagnóstico de MII em mulher jovem com dispneia progressiva e DPI, sem acometimento muscular expressivo e com lesões dermatológicas incipientes. $O$ painel de anticorpos de miopatias com anti-MDA-5 positivo, embora pouco disponível na prática clínica, foi de extrema importância para a confirmação da DPI por DM amiopática com comprometimento pulmonar mais agressivo, corroborando para o tratamento imunossupressor instituído.

\section{Referências Bibliográficas}

Fischer et al. EurResp J. 2015;46:976-987

Barbaet al. SeminRespirCrit Care Med. 2019;40:255-270.

Solomon et al. J Bras Pneumol. 2011;37(1):100-109.

Concha et al. J Am AcadDermatol. 2018;78:769-775.

Moghadam-Kia et al. Arthritis Care Res. 2016:68(5):689-694.

Cojocaru et al. MAEDICA - a Journal Of Clinical Medicine. 2016;1192:130135 